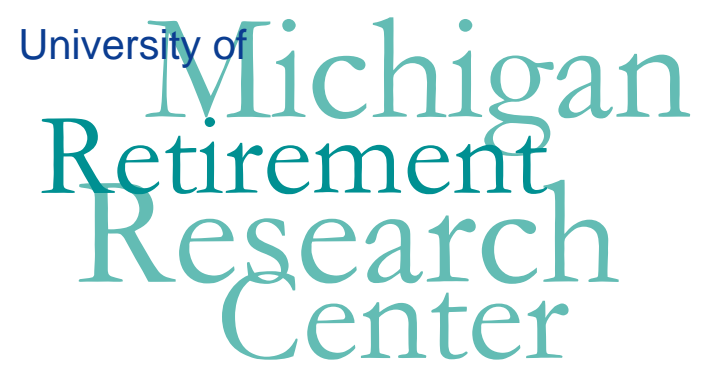

Working Paper

WP 2009-218

\title{
The Level and Risk of Out-of-Pocket Health Care Spending
}

\author{
Michael D. Hurd and Susann Rohwedder
}

\begin{tabular}{|l|l|l|l|l|l|l}
\hline $\mathrm{M}$ & $\mathrm{R}$ & Project \#: UM09-08 \\
\hline $\mathrm{R}$ & $\mathrm{C}$ & \\
\hline
\end{tabular} 



\title{
The Level and Risk of Out-of-Pocket Health Care Spending
}

\author{
Michael D. Hurd \\ RAND \\ Susann Rohwedder \\ RAND \\ September 2009 \\ Michigan Retirement Research Center \\ University of Michigan \\ P.O. Box 1248 \\ Ann Arbor, MI 48104 \\ http://www.mrrc.isr.umich.edu/ \\ (734) 615-0422
}

\section{Acknowledgements}

This work was supported by a grant from the Social Security Administration through the Michigan Retirement Research Center (Grant \# 10-M-98362-5-01). The findings and conclusions expressed are solely those of the author and do not represent the views of the Social Security Administration, any agency of the Federal government, or the Michigan Retirement Research Center.

Regents of the University of Michigan

Julia Donovan Darrow, Ann Arbor; Laurence B. Deitch, Bingham Farms; Denise Ilitch, Bingham Farms; Olivia P. Maynard, Goodrich; Andrea Fischer Newman, Ann Arbor; Andrew C. Richner, Grosse Pointe Park; S. Martin Taylor, Gross Pointe Farms; Katherine E. White, Ann Arbor; Mary Sue Coleman, ex officio 


\title{
The Level and Risk of Out-of-Pocket Health Care Spending
}

\begin{abstract}
The Health and Retirement Study (HRS) is a long-running panel survey with good measures of economic status, so it is the pre-eminent data set for studies about the economic status of the older population and economic preparation for retirement. However, the HRS expends considerably fewer resources on the measurement of out-of-pocket spending than other surveys such as the Medical Expenditure Panel Survey (MEPS) and the Medicare Current Beneficiary Survey (MCBS), which may result in its having relatively less accurate measurement of such spending. We compare the level and distribution of out-of-pocket spending in the HRS with similar measures in MEPS and MCBS in the population aged 65 or older. We find that the measures of out-of-pocket spending in the HRS are about 50\% greater than those in MEPS at the mean, and very much greater at the upper points of the distribution. HRS and MCBS are in better agreement, although the HRS is higher at the mean and at the top of the distribution. The implication is that the level and risk of out-of-pocket spending on health care are exaggerated in HRS. Observation error in the HRS measurement relative to MEPS and MCBS is to be expected, but this does not explain the apparent bias. We conclude that researchers who use HRS 2004 or earlier should examine health care spending carefully, even on a case-by-case basis.
\end{abstract}

\section{Authors’ Acknowledgements}

We are grateful to the Social Security Administration for this research support. 


\section{Introduction}

Because of the general increase in health care costs, out-of-pocket spending for health care is becoming increasingly important from the point of view of the public, of public policy and of scientific studies of economic behavior. For example, economic preparation for retirement is of substantial policy concern. Yet, there is considerable controversy about the level of preparation. Hurd and Rohwedder (2006) show that the spending levels of most households shortly following retirement are consistent with their economic resources and projected paths of spending. In fact a considerable fraction of households will die with leftover wealth. Others, however, maintain that households are not well prepared financially for retirement. For example, the National Retirement Risk Index produced by the Center for Retirement Research at Boston College asserts that $61 \%$ of households are at risk of not having enough to maintain their living standards in retirement (Munnell et al., 2008). Part of the difference in these findings is the estimation of current out-of-pocket spending on health care costs and projections for future costs.

Economic models of life-cycle saving and retirement that account for uncertainty of health status and health care spending use data about the level and distribution of out-of-pocket health care costs, and, in some cases, the model estimations depend critically these data. For example, in De Nardi, French and Jones (2006) a few very large out-of-pocket expenditures by people in their late 90s have, in their estimated model, an important influence on the rate of wealth change among people in their 70s. Yet, we have little understanding of the accuracy of these measurements.

We emphasize two major reasons why understanding the level and risk of out-of-pocket spending health care is important for public policy. First, the adequacy of economic preparation for retirement depends on current out-of-pocket spending for health care, its future path, and the path of the distribution of spending. Second, if budgetary constraints of Medicare require increases in out-of-pocket spending by the elderly we would like to know what the current situation actually is.

The main goal of this paper is to assess the level and distribution of out-of-pocket spending on health care in the Health and Retirement Study (HRS) and to compare these measures with similar measures from the Medical Expenditure Panel Survey (MEPS) and the 
Medicare Current Beneficiary Survey (MCBS). We focus on the HRS because it is the preeminent data set for studies about the economic status of the older population and economic preparation for retirement, and for the estimation of models of retirement and saving behavior. Such studies require good data on economic resources which is an important feature of the HRS; the value of HRS is further increased by its being a very long panel. However, the HRS expends considerably fewer resources on the measurement of out-of-pocket spending than either the MEPS or the MCBS, so we presume their measures are more accurate than the HRS measures.

We limit the analysis to the population aged 65 or older because of the greater level of spending in the older population. Furthermore, the MCBS is approximately populationrepresentative of that population, but not of the younger population.

2. Major issues in the measurement and interpretation of out-of-pocket spending on health care

Measurement. Because there is no central registry of out-of-pocket spending on health care, measures must rely on household surveys. Self-reports are subject to recall error, ambiguity, anchoring and so forth. As an empirical matter, reports of out-of-pocket spending vary considerably by source. Consider, for example, out-of-pocket spending excluding health care insurance as measured in Health and Retirement Study (HRS) the Medical Expenditure Panel Survey (MEPS) and the Medicare Current Beneficiary Survey (MCBS). The mean amounts differ considerably. In the 2004 HRS, which approximately covers the years 2002 and 2003, the HRS measured average out-of-pocket spending as \$2200 per year among those 70-74. The 2003 MCBS estimate was $\$ 1500$ and the 2003 MEPS estimate was $\$ 1400$. These just show variation in the means; of course both for public policy and for economic modeling the distribution is important (to be discussed below).

Type of spending.

Spending on drugs prior to 2006 will differ from spending in 2006 or later because of Medicare Part D. ${ }^{1}$ Thus, what we can find in the latest public release of HRS (2006) for drug spending is not a very good guide of what we will find in HRS 2008 and later waves.

\footnotetext{
${ }^{1}$ Even spending in 2006 is not strictly comparable with spending in 2007 and later because of part-year enrollment associated with the start-up of Part D.
} 
Spending on nursing home requires particular consideration from a theoretical point of view. Because of Medicaid, amounts spent by a single person on long-term end-of-life stay have practically no value. Said differently, except for considerations of the quality of the nursing home, the optimal wealth path ex post will reach zero at nursing home entry. While a single 70 year-old will engage in buffer stock saving to be able to meet contingency spending for medical services and drugs, he or she will not engage in buffer stock saving to be able to meet nursing home costs. Economic models that treat out-of-pocket spending by single people on nursing homes in the same manner as spending on other health care costs will misestimate utility function parameters and the welfare costs of buffer stock saving. These considerations are likely to be quantitatively important because most long-term residents of nursing homes are single women for whom out-of-pocket spending for nursing home stays has no value. For a couple where one spouse must enter a nursing home for long-term stay the situation is quite different. Money spent on the nursing home has value to the other spouse. However, because the healthy spouse typically cares for the unhealthy spouse until that spouse is very unhealthy (and therefore closer to death) it is relatively infrequent that one spouse is in long-term nursing home stay and the other spouse is in the community. For these reasons, long-term care insurance is not particularly valuable which implies that the perceived utility loss associated with the risk of outof-pocket spending on nursing homes is not large (Brown and Finkelstein, 2004).

Household composition. It is important to distinguish household composition because the interpretation of out-of-pocket spending by a couple is different from that for a single person. The case of the nursing home is especially relevant. But in addition the expected lifetime of a couple is relatively short which means that the high level of spending by a couple will not persist for the expected lifetime of either spouse.

Life-cycle spending versus cross-section spending. Although statements about the age variation in out-of-pocket spending typically depend on observations of spending in crosssection data, spending on health care services will follow a life-cycle path that differs from observations in cross-section. Just as life-cycle wealth paths cannot be inferred from crosssection wealth levels, so life-cycle paths of out-of-pocket spending on health care cannot be inferred from cross-section levels. The reasons are essentially the same: younger cohorts have more economic resources than older cohorts did at comparable ages, and those with more economic resources spend more out-of-pocket than those with fewer resources. For example, in 
the Consumption and Activities Mail Survey (CAMS) out-of-pocket spending adjusted for age is about \$2000 greater among couples in the top wealth quartile than among couples in the bottom wealth quartile. For singles the difference is about $\$ 1700$. Because the wealthy survive longer than the poor, average spending by survivors will increase with age even if there is no change in spending by individuals.

\section{Data}

Our main data set is the Health and Retirement Study (Juster and Suzman, 1995). The HRS is a biennial panel survey that collects data on a wide range of economic, labor force and health topics from about 20,000 persons aged approximately 51 or older. ${ }^{2}$ Because it has complete measures of income, wealth and pension rights, it is the premier data set for studying retirement, saving behavior and economic preparation for retirement. The HRS queries about all categories of out-of-pocket spending on health care services including prescription drugs. However, it spends less interviewing effort on such spending relative to several other surveys, raising the possibility that its measure has greater variance and possible bias compared with measures from other surveys.

The Medical Expenditure Panel survey is a rotating two-year household panel survey of community-dwelling persons. Because its main focus is on health care spending it spends considerable survey effort in accurate data collection. In addition to the household survey, MEPS includes a medical provider component (including pharmacies) that obtains additional data on health care spending. The providers are identified by the respondent and the data obtained from them augment the self-reports. Because of the substantial effort expended on their collection we expect the MEPS data to be of high quality. However, the MEPS has two drawbacks. It does not include nursing home residents, and so has incomplete data on an important component of out-of-pocket spending; its sample of the older population is small relative to the HRS.

The Medicare Current Beneficiary Survey is a rotating four-year panel survey of persons enrolled in Medicare Part A or B or both who may reside in the community or in long-term care facilities. The MCBS has a focus on health and functional status, health care expenditures and

\footnotetext{
${ }^{2}$ See http://hrsonline.isr.umich.edu/
} 
health insurance, and spends extra effort relative to the HRS to obtain data on these elements. In particular

“...respondents are requested to record medical events on calendars provided by the interviewer, and they are also asked to save Explanation of Benefit forms from Medicare, as well as receipts and statements from private health insurers. To assist in reporting data on prescription medicines, respondents are asked to bring to the interview bottles, tubes, and prescription bags provided by the pharmacy."3

We expect that these written records and additional effort will produce high quality data on health care spending. The main drawback of the MCBS is that its coverage of the population less than 65 is limited to disabled enrollees.

\section{Results}

We give an example of measuring out-of-pocket spending in the HRS in Table 1. It shows measured out-of-pocket spending by single persons in three waves of HRS data merged. The mean increases sharply with age; the median also increases at about the same percentage rate but it is much lower. The 90th percentile is much larger than the median. The maximum is very large indeed leading to doubt that it was accurately measured.

Spending in general, and not just for health care services, is difficult to measure because of recall error, so that extreme values may be partly due to measurement error. To investigate that issue we present in Table 2 data relating to spending by households, where in the case of couples we have summed spending by both spouses. The table shows spending by the top $1 \%$ of spenders and by the top 10 spenders. The spending data come from merged HRS waves in 2002, 2004 and 2006 and are referred to as spending at t. In the top 1\%, mean two-year spending is recorded to be about $\$ 116$ thousand. We ask whether independent data suggest these households could have spent that amount. Household income in the wave preceding the measurement of spending averaged about \$39 thousand; wealth in the preceding wave was about $\$ 407$ thousand and wealth in the same wave averaged $\$ 383$ thousand. ${ }^{4}$ Thus during the two years of spending, total income was about $\$ 78(2 * \$ 39)$ thousand and wealth declined by $\$ 24$ thousand. ${ }^{5}$ In the absence of any revaluation of wealth, these figures imply that the households spent \$102

\footnotetext{
${ }^{3} 2003$ Appendix A. Technical Documentation For the Medicare Current Beneficiary Survey accessed from /mcbs/downloads/HHC2003appendixA.pdf

${ }^{4}$ Because we have not selected on large values of income or wealth, we presume our measures of those quantities are unbiased.

${ }^{5}$ Income changed very little between $\mathrm{t}-2$ and t so we just use income measured at $\mathrm{t}-2$.
} 
thousand on all spending items. Thus they could not have spent \$116 thousand on health care. If we think that only financial wealth is available to finance health care spending the implication is the same.

The medians show in a similar way that the large values of out-of-pocket spending are likely to include substantial observation error: median two-year income plus wealth reduction totaled about \$58 thousand, yet median two-year out-of-pocket spending was about \$90 thousand. Spending by the top 10 spenders is even more obviously strongly influenced by observation error: mean spending was \$477 thousand yet total assets at t-2 were just \$283 thousand.

A possible reason for the observation error is imputation for item nonresponse. The HRS asks about the use of health care services in a number of categories such as out-patient doctor visits. If a respondent affirms service use, she is asked about out-of-pocket spending. Most respondents with service use report a value but some responded with a “don't know” or “refuse.” Follow-up bracketing questions place the spending in a range such as $\$ 2,500-\$ 3,000$, and, in the processing of the data for public release, values of such components of total spending are imputed. To address the issue of whether imputation is responsible for the outliers, in Table 3 we show average spending, income and wealth among those households whose spending is in the middle $20 \%$ of the spending distribution (i.e. from the $40^{\text {th }}$ to the $60^{\text {th }}$ percentile). The respondents are classified according to whether any out-of-pocket spending item was imputed. Among those in the middle of the distribution of out-of-pocket spending the rate of item nonresponse is fairly low: just 23\% of respondents had an imputation for any item of spending. Spending is approximately independent of imputation status as are income and wealth. There is little wealth change, implying that out-of-pocket spending for health care was financed out of income.

For comparison in Table 4 we show the same statistics for those households in the top 1\% of the distribution of out-of-pocket spending. The rate of imputation is much greater: about $53 \%$ of households had at least one imputation. This higher rate is to be expected: high spenders will have spending in more categories, resulting in higher total risk of item nonresponse in at least one category. But what is notable is that spending is even a little higher among those with no imputations. It is also notable that both income and wealth are higher, providing some validation for the higher average because out-of-pocket spending is a normal good. We conclude 
that imputation may contribute to the large outliers in spending, but they are not primarily responsible for them.

Out-of-pocket spending on prescription drugs is particularly difficult to measure in a household survey because of the heterogeneity in purchasing patterns. Some people take a particular medication on a regular monthly basis: for them a single question about monthly spending will, when annualized, give a good estimate of yearly spending. Other people take drugs only infrequently in response to a health event: during a health episode spending may be substantial. Annualizing spending from a particular month will result in no spending among a large group of such people, and in a very large value among a small group. The population average will be accurate but the process will generate large outliers.

The HRS in 2004 asked those who say they "regularly take prescription medications" the following question about costs:

\section{On average, about how much have you paid out-of-pocket per month for these prescriptions in the last two years? ${ }^{6}$}

This monthly amount is then converted to a two-year measure by multiplying by 24. Error can be introduced by respondents reporting actual spending in the last month or two even though spending is episodic. More serious error would occur if a respondent reported a yearly amount rather than an monthly amount. In any case it is likely to be difficult for a respondent to remember the details of spending over a 24 month period and to be able to report an average monthly amount.

To find how the measurement of spending on drugs affects the distribution of spending, we compare total out-of-pocket spending by individuals with out-of-pocket spending excluding spending on prescription drugs. Table 5 shows that there are large differences in measured spending according to whether drugs are included. For example, the overall mean is more than twice as large when drug spending is included, and the median is even greater as a proportion. The differences persist throughout the distribution, although in the highest age bands the difference is diminished.

\footnotetext{
${ }^{6}$ In 2006 HRS changed the questions about spending for prescription drugs because of the introduction of Medicare Part D. Apparently as a consequence estimated spending for prescription drugs dropped substantially.
} 
Both the MEPS and MCBS are more focused on health and health care spending than the HRS and so expend greater effort in the collection of spending data. As such they provide good reference points against which to compare HRS spending. However, an important limitation of the MEPS is that it only includes community-residing persons; that is, it excludes nursing home residents. Therefore, in comparisons of HRS and MCBS with MEPS we limit them to the community-based population.

Table 6 shows measured out-of-pocket spending from the HRS, MCBS and MEPS. Mean levels are always higher in the HRS than in the MCBS or the MEPS. From the point of view of risk, that is the probability of very large out-of-pocket spending, the HRS records much higher values: in the age band 65-69, the $90^{\text {th }}$ percentile is $\$ 3750$ in the HRS compared with about $\$ 3000$ in the MEPS and \$2700 in the MCBS. This difference at the $90^{\text {th }}$ percentile persists qualitatively at all age bands. But particularly at the $99^{\text {th }}$ percentile the differences between the three surveys are substantial. For example, in the age band 85 or older, the HRS records much higher values than the MCBS or MEPS, but the latter two are certainly not in agreement. To the extent that the absence of outliers signals better data quality, the MEPS seems to be a more accurate source of data on out-of-pocket spending. However, spending on nursing homes is an important aspect of total spending, and the population of nursing home residents is an important sub-population both from the scientific and from the policy perspectives. The lack of data on that population makes MEPS less useful than were it to cover the entire population.

Table 7 has a similar comparison between HRS and MCBS, which cover the entire population aged 65 or older. The medians are remarkably similar for all and in all age bands. The means for all are similarly close but at younger ages the HRS means are abut 50\% higher. This difference is due to some large outliers in HRS at younger ages. For example, in the age band 65-69 the 99th percentile in the HRS is about \$26 thousand compared with just \$12 thousand in MCBS. This difference in the $99^{\text {th }}$ percentile does not persist at older ages, however, where the entire distributions are very close. It is not at all obvious why there should be such differences at younger ages but not at older ages.

5. Persistence of spending at the household level. 
The spending levels and distributions that we have presented are cross-section and describe spending in the population at a moment-in-time by age. However, the risk of very large spending should be ascertained over time because of serial correlation in spending at the individual level: some individuals have persistently bad health and are, therefore, persistently high spenders, and some individuals have persistently good health and are, therefore, persistently low spenders. We illustrate this persistence by transition probabilities between spending quartiles, the probability that spending will be in some particular quartile in wave $t$, conditional on spending quartile in wave t- 1 . Table 8 has such probabilities for single persons. The probabilities are averaged over three transitions between four waves of HRS, 1998, 2000, 2002 and 2004. Were spending perfectly persistent the conditional probabilities would all lie on the diagonal; were there no persistence there would be 25 percent probabilities in each cell. It is apparent that there is considerable persistence, but by no means is it complete. For example, the probability that someone with spending in the lowest quartile in wave t- 1 would have spending in the lowest quartile in wave $\mathrm{t}$ is almost $60 \%$; yet, the probability that person would have spending in the highest quartile in wave $t$ is about $9 \%$.

Table 9 has analogous transition probabilities for married persons, but the persistence is a little weaker than for single persons. This is to be expected because of the greater likelihood that one of two people will change spending levels compared with the likelihood that just one person will.

An implication of Tables 8 and 9 is that the distribution of spending in panel data will be different from a scaled-up cross-section distribution. In our previous comparisons between HRS, and MCBS and MEPS, we converted two-year HRS figures to one-year figures by dividing the HRS quantities by two. This calculation should preserve means, but not the other points on the distribution. For example, the maximum spender in one year is unlikely to be the maximum spender in the succeeding year. Thus the two-year maximum will be less than the sum of the one-year maxima when the one-year maxima are calculated without respect to the panel nature of the data. Similarly at the bottom of the distribution the two-year minimum will be greater than the sum of the one-year minima. An implication is that the method we used in calculating the MCBS and MEPS distributions inflates the variance of two-year spending relative to the variance of actual two-year spending. 
We show this in Table 10 which has several measures of the distribution of spending from MCBS and MEPS. The entries labeled "MEPS sum" simply add the quantiles from 2002 MEPS and 2003 MEPS. For example, among those 65-69 the $10^{\text {th }}$ percentile (p10) was $\$ 50$ in 2002 MEPS and it was $\$ 39$ in 2003 MEPS (not shown), so that p10 of "MEPS sum” is $\$ 89$. These values should be about twice the values for MEPS in Table 6: any differences are due the use of MEPS 2002 in Table 10 and to the use of a sample restricted to those who were in both MEPS 2002 and 2003. The entries labeled "MEPS panel" give the quantiles of the sum of 2002 and 2003 spending in panel. Both "MEPS sum" and "MEPS panel” use the same observations. The entries for "MCBS sum" and "MCBS panel” are calculated in a similar manner over spending by 65-69 year-olds in the MCBS. The last panel of Table 10 has analogous figures for the population 65 or older.

It is apparent that summing the cross-section quantiles inflates the measure of variance relative to the panel quantiles. For example, the $99^{\text {th }}$ percentile of spending in MEPS panel among those 65-69 is $\$ 11,278$ compared with the sum of the 99th percentiles $(\$ 14,638)$. At the bottom of the distribution the differences are much smaller in absolute value (although not in relative terms) and also act to increase variance. The levels and pattern in MCBS are similar and also show an increase in variance.

An implication is that our comparisons of HRS with MEPS and MCBS in Tables 6 and 7 understated the difference in variance: had we used panel measures of variance for MEPS and MCBS the differences between them and HRS would have been even greater. A more accurate comparison should be based on MEPS and MCBS panels.

Table 11 has such comparisons. The population is restricted to the non-institutionalized population so that we can use MEPS. Spending in HRS is measured in 2004 as approximately two-year spending "since the last interview," which we take to be spending in 2002 and 2003. Therefore we compare 2004 spending in HRS with the sum of spending in 2002 and 2003 from MCBS and from MEPS over panel observations. ${ }^{8}$ The HRS entries are just twice the entries in

\footnotetext{
${ }^{7}$ Sample sizes for MEPS panel are considerably smaller than the 2003 cross-section sample because MEPS is a twoyear panel: the 2003 cross-section as in Tables 6 and 7 uses observations from the 2002 and 2003 panels whereas the MEPS panel observations are based on just the 2002 panel. We used this same reduced sample in the "MEPS sum" so as to compare spending across the same populations.

${ }^{8}$ There is a (small) mismatch between the spending reference period: a median HRS respondent would have been interviewed in about June 2004 so that spending would refer to the latter half of 2002, 2003 and the first half of 2004. MEPS and MCBS spending refers to 2002 and 2003. We have not attempted to correct for this mismatch which would vary for each HRS respondent.
} 
Table 6. The MCBS and MEPS means are about $8 \%$ and $7 \%$ higher than twice the means in Table 6. In principal these measures should be the same, and the difference implies that survivors in panel have somewhat higher spending than those who do not survive in panel. ${ }^{9}$ This difference is to be expected because higher income and wealth are associated with higher survivor probabilities, and those with greater income and wealth tend to spend more out-ofpocket. The major difference, however, is between HRS and the other two surveys: among those 65-69, mean spending in HRS is about twice as great, and among all those 65 or older mean spending is about 50\% higher. At the upper part of the distributions the differences are considerable greater.

We have based our results on HRS 2004, but it is possible that HRS in other years is closer to MCBS and MEPS, and so we would like to make at least one other comparison. HRS 2006 cannot be easily compared with prior waves of HRS. Because of the introduction of Medicare Part D, the HRS question sequence about spending on prescription drugs was altered. Possibly as a consequence, measured drug spending was substantially lower than in 2004, even among those not affected by Part D. Furthermore, HRS 2006 cannot easily be compared with either MCBS or MEPS because the appropriate reference period for those surveys is prior to the introduction of Part D whereas the HRS reference period partly includes Part D participation for some HRS respondents. Therefore, we compare HRS 2002 with MCBS and MEPS 2000 and 2001. These comparisons are shown in Table 12, and they are calculated in the same manner as those in Table 11. They show the same general levels and patterns as the comparisons in Table 11.

In Table 13 we summarize the comparisons between the measures of out-of-pocket spending. We take the measurements in MEPS to be the most accurate because of the greater survey effort. The table shows the percentage difference between the MEPS measurement and the HRS measurement, and between the MEPS measurement and the MCBS measurement, in all cases calculated over the population 65 or over, and, in the case of MEPS and MCBS, in panel. Two-year spending in 2002 and 2003 was 56.5\% higher at the mean as measured in HRS 2004

\footnotetext{
${ }^{9}$ Both calculations ignore end-of-life spending as they are based on interviews with survivors.
} 
than it was as measured in MEPS in 2002 and 2003. The MCBS was just 1.3\% higher than the MEPS measure. At the $95^{\text {th }}$ percentile HRS is 55.5\% higher than MEPS. ${ }^{10}$

These 2002 and 2003 percentage deviations are similar to the 2000 and 2001 percentage deviations as shown in the bottom of the table. At least for this additional comparison the HRS records substantially greater out-of-pocket spending health care spending than either MCBS or MEPS.

\section{Conclusions}

The measures of out-of-pocket spending in the HRS are about 50\% greater than those in MEPS at the mean, and very much greater at the upper points of the distribution. HRS and MCBS are in better agreeement, althougth the HRS is higher at the mean and at the top of the distribution. The implication is that the level and risk of out-of-pocket spending on health care are exaggerated in HRS. Observation error in the HRS measurement relative to MEPS and MCBS is to be expected because HRS is a general purpose survey with two-year periodicity, and so it cannot expend the resources on the measurement of spending that MCBS and MEPS are able to do. But this does not explain the apparent bias.

A suggestion for researchers using data from the HRS waves of 2004 or earlier would be to examine health care spending on a case-by-case basis looking for patterns in the panel data that would indicate large observation error. For example, if someone does not have the resources to support financially the reported spending, there may be a presumption of positive observation error. This type of case-by-case analysis is difficult, however, because of the arbitrariness of which observations to classify as in error and which observations not to classify. An alternative is to use simple Bayesian methods to shrink reported spending to a prior benchmark. The benchmark would be spending in MEPS and the amount of shrinkage would be related to the variance of spending in the HRS relative to MEPS.

Beginning with HRS 2006 actual out-of-pocket spending on prescription drugs should decline because of Medicare Part D. But, more importantly the risk of large out-of-pocket spending will be sharply reduced for the great majority of those 65 or older because of protection

\footnotetext{
10 This number is calculated from the 95th percentile in HRS of $\$ 13,100$ and the $95^{\text {th }}$ percentile in MEPS of $\$ 8411$ (Table 11).
} 
against catastrophic drug spending. Thus our comparisons of spending from HRS with spending from MEPS and MCBS will not be relevant for these later waves of HRS. 


\section{References}

Brown, Jeffrey, and Amy Finkelstein, 2004, "Supply or Demand: Why is the Market for LongTerm Care Insurance So Small?” NBER Working Paper 10782.

De Nardi, Mariacristina, Eric French, and John Bailey Jones, 2006, "Differential Mortality, Uncertain Medical Expenses, and the Saving of Elderly Singles,” Working Paper 200513, Federal Reserve Bank of Chicago

Hurd, Michael D. and Susann Rohwedder, 2006, “Alternative Measures of Replacement Rates,” University of Michigan Retirement Research Center, WP 2006-132.

Juster, F. T. and Richard Suzman, 1995, “An Overview of the Health and Retirement Study,” Journal of Human Resources, 30, S7-S56.

Munnell, Alicia, Mauricio Soto, Anthony Webb, Francesca Golub-Sass, and Dan Muldoon, 2008, "Health Care Costs Drive Up the National Retirement Risk Index,” IB\#8-3, Center for Retirement Research at Boston College. 


\begin{tabular}{lrrrrrrrr}
\hline \multicolumn{1}{l}{ Table 1. Distribution of two-year out-of-pocket spending by single persons, pooled HRS 2002, } \\
2004, 2006 (2004\$) \\
\hline & & \multicolumn{7}{c}{ Percentile points } \\
& Mean & 0 & 10 & 25 & 50 & 75 & 90 & 100 \\
\hline $65-69$ & 3168 & 0 & 0 & 147 & 952 & 2701 & 6440 & 555994 \\
$70-74$ & 3716 & 0 & 0 & 203 & 1024 & 3136 & 7070 & 400798 \\
$75-79$ & 4455 & 0 & 0 & 365 & 1350 & 3600 & 7550 & 492619 \\
$80-84$ & 5064 & 0 & 0 & 368 & 1452 & 3863 & 8674 & 576800 \\
85 or older & 8251 & 0 & 0 & 253 & 1543 & 5486 & 19960 & 233675 \\
\hline
\end{tabular}

Source: Authors' calculations

Table 2. Two-year average out-of-pocket spending by households between years $\mathrm{t}-2$ and $\mathrm{t}$ and income and wealth. Average of top 1\% of spenders and of top 10 observations. Pooled HRS 2002, 2004, $2006(2004 \$)$

\begin{tabular}{lrrrr}
\hline & \multicolumn{2}{c}{ top 1\% } & \multicolumn{2}{c}{ top 10 observations } \\
\cline { 2 - 5 } & Mean & Median & Mean & Median \\
\cline { 2 - 5 } OOP spending & 115,877 & 90,247 & 477,321 & 434,213 \\
Household income & 38,698 & 24,173 & 48,874 & 13,585 \\
Household wealth at t-2 & 407,079 & 145,000 & 282,912 & 113,917 \\
Household wealth at t & 383,787 & 134,929 & 328,792 & 78,338 \\
Household financial wealth at t-2 & 205,049 & 31,593 & 52,790 & 2,100 \\
Household financial wealth at t & 171,988 & 26,000 & 18,803 & 5,000 \\
\hline
\end{tabular}

Source: Authors' calculations

Table 3. Two-year out-of-pocket spending, income and wealth of households by middle $20 \%$ of spenders by whether any spending was imputed. Age 65 or older.

Pooled HRS 2002, 2004, 2006 (2004\$)

\begin{tabular}{lrrrrr}
\hline & \multicolumn{1}{c}{ N } & spending & income & wealth t-1 & wealth t \\
\cline { 2 - 6 } Means & & & & & \\
no imputations & 5382 & 3551 & 50945 & 455800 & 506026 \\
some imputations & 1622 & 3718 & 45846 & 425798 & 432231 \\
& & & & & \\
Medians & & & & & \\
no imputations & 5382 & 2004 & 34491 & 210000 & 219451 \\
some imputations & 1622 & 1977 & 29448 & 197715 & 208750 \\
\hline
\end{tabular}

Source: Authors' calculations 
Table 4. Two-year out-of-pocket spending, income and wealth of

households by top $1 \%$ of spenders by whether any spending was imputed.

Age 65 or older. Pooled HRS 2002, 2004, 2006 (2004\$)

\begin{tabular}{|c|c|c|c|c|c|}
\hline & $\mathrm{N}$ & spending & income & wealth $\mathrm{t}-1$ & wealth $\mathrm{t}$ \\
\hline $\begin{array}{l}\text { Means } \\
\text { no imputations }\end{array}$ & 213 & 120375 & 46572 & 537279 & 537007 \\
\hline some imputations & 244 & 90249 & 32126 & 333707 & 282335 \\
\hline $\begin{array}{l}\text { Medians } \\
\text { no imputations } \\
\text { some imputations }\end{array}$ & $\begin{array}{l}213 \\
244\end{array}$ & $\begin{array}{l}86853 \\
77280\end{array}$ & $\begin{array}{l}34004 \\
19538\end{array}$ & $\begin{array}{r}215118 \\
87758\end{array}$ & $\begin{array}{r}236256 \\
86314\end{array}$ \\
\hline
\end{tabular}

Source: Authors' calculations

Table 5. Annualized out-of-pocket spending by individuals, total and total excluding drugs. HRS 2004.

Source: Authors' calculations 
Table 6. Annual out-of-pocket spending on health care services by individuals 2003. Excludes nursing home residents. Average, median, $90^{\text {th }}, 95^{\text {th }}$ and $99^{\text {th }}$ percentile points. Weighted.

\begin{tabular}{llrrrrrr}
\hline Age & Data & $\mathrm{n}$ & mean & $\mathrm{p} 50$ & $\mathrm{p} 90$ & $\mathrm{p} 95$ & $\mathrm{p} 99$ \\
\hline $65-69$ & HRS & 3339 & 2017 & 720 & 3750 & 5785 & 21950 \\
& MCBS & 2148 & 1309 & 713 & 2672 & 4171 & 9601 \\
& MEPS & 977 & 1232 & 676 & 2963 & 4055 & 8539 \\
$70-74$ & HRS & 2605 & 2219 & 750 & 4320 & 6750 & 25320 \\
& MCBS & 2105 & 1543 & 851 & 3158 & 4599 & 9847 \\
& MEPS & 967 & 1401 & 816 & 3233 & 4903 & 8332 \\
$75-79$ & HRS & 1982 & 2387 & 880 & 4075 & 6015 & 21650 \\
& MCBS & 1934 & 1658 & 923 & 3373 & 5038 & 11908 \\
& MEPS & 762 & 1626 & 887 & 3553 & 5016 & 9826 \\
80-84 & HRS & 1529 & 2363 & 980 & 4550 & 8420 & 28900 \\
& MCBS & 1809 & 1646 & 938 & 3354 & 4745 & 12799 \\
& MEPS & 507 & 1833 & 1075 & 3419 & 4888 & 8878 \\
85 or over & HRS & 1166 & 2398 & 950 & 5400 & 7500 & 25150 \\
& MCBS & 1568 & 1931 & 1005 & 4289 & 5985 & 17800 \\
& MEPS & 367 & 1864 & 1087 & 4293 & 6130 & 10949 \\
All & HRS & 10621 & 2240 & 810 & 4200 & 6550 & 24610 \\
& MCBS & 9564 & 1563 & 854 & 3242 & 4743 & 11447 \\
& MEPS & 3580 & 1514 & 828 & 3379 & 4888 & 9315 \\
\hline
\end{tabular}

Source: Authors' calculations based on 2003 MCBS and MEPS and 2004 HRS. 
Table 7 Out-of-pocket spending by individuals, including nursing home residents, HRS and MCBS. 2003. Weighted

\begin{tabular}{|c|c|c|c|c|c|c|c|c|c|c|}
\hline \multirow[b]{2}{*}{ HRS } & \multirow[b]{2}{*}{$\mathrm{N}$} & \multirow[b]{2}{*}{ mean } & \multicolumn{7}{|c|}{ Percentile points } & \multirow[b]{2}{*}{$\max$} \\
\hline & & & $\mathrm{p} 10$ & p25 & p50 & p75 & p90 & p95 & p99 & \\
\hline $65-69$ & 3368 & 2086 & 5 & 220 & 720 & 1800 & 3767 & 5850 & 25580 & 420000 \\
\hline $70-74$ & 2646 & 2354 & 0 & 240 & 755 & 1925 & 4530 & 7200 & 28800 & 218250 \\
\hline $75-79$ & 2024 & 2566 & 0 & 300 & 892 & 2080 & 4200 & 6426 & 30050 & 268250 \\
\hline $80-84$ & 1603 & 2957 & 32 & 300 & 1000 & 2310 & 5200 & 11270 & 36405 & 180750 \\
\hline $85+$ & 1422 & 4405 & 0 & 240 & 1020 & 3400 & 9600 & 24540 & 60588 & 127245 \\
\hline All & 11063 & 2677 & 0 & 250 & 830 & 2126 & 4750 & 8100 & 36006 & 420000 \\
\hline \multicolumn{11}{|l|}{ MCBS } \\
\hline $65-69$ & 2183 & 1403 & 64 & 276 & 720 & 1513 & 2833 & 4354 & 11538 & 133511 \\
\hline $70-74$ & 2140 & 1673 & 115 & 388 & 862 & 1783 & 3329 & 4847 & 11861 & 132147 \\
\hline 75-79 & 2016 & 2136 & 135 & 441 & 946 & 1924 & 3897 & 6189 & 29939 & 81950 \\
\hline $80-84$ & 2000 & 2942 & 146 & 451 & 1026 & 2196 & 5069 & 12125 & 37502 & 241122 \\
\hline $85+$ & 2048 & 4790 & 156 & 481 & 1295 & 3674 & 12037 & 25260 & 53553 & 93172 \\
\hline All & 10387 & 2324 & 110 & 384 & 898 & 1942 & 4171 & 7533 & 33691 & 241122 \\
\hline
\end{tabular}

Source: Authors' calculations based on 2003 MCBS and 2004 HRS.

Table 8. Percent distribution of out-of-pocket spending in wave t conditional on spending quartile in wave t-1, HRS waves 1998, 2000, 2002 and 2004. Single persons. Panel

\begin{tabular}{lrrrrr}
\hline & \multicolumn{5}{c}{ quartile in wave t } \\
\cline { 2 - 5 } quartile in wave t-1 & lowest & 2nd & 3rd & highest & all \\
\hline lowest & 58.8 & 20.8 & 11.8 & 8.7 & 100.0 \\
$2^{\text {nd }}$ & 19.9 & 41.2 & 24.7 & 14.1 & 100.0 \\
$3^{\text {rd }}$ & 9.3 & 23.9 & 39.9 & 26.9 & 100.0 \\
highest & 8.6 & 12.3 & 24.7 & 54.5 & 100.0 \\
\hline
\end{tabular}

Source: Authors' calculations 
Table 9. Percent distribution of spending in wave t conditional on spending quartile in wave t-1, HRS waves 1998, 2000, 2002 and 2004. Married persons. Panel

\begin{tabular}{lrrrrr}
\hline & \multicolumn{4}{c}{ quartile in wave t } & all \\
\cline { 2 - 5 } quartile in wave t-1 & lowest & 2nd & 3rd & highest & 100.0 \\
\hline lowest & 47.1 & 26.4 & 15.6 & 11.0 & 100.0 \\
$2^{\text {nd }}$ & 22.2 & 33.0 & 26.1 & 18.8 & 100.0 \\
$3^{\text {rd }}$ & 13.3 & 24.1 & 34.3 & 28.2 & 100.0 \\
\hline
\end{tabular}

Source: Authors' calculations

Table 10. Two measures of the distribution of two-year total out-of-pocket spending by individuals. Non-institutionalized population. MEPS and MCBS 2002 and 2003. Weighted

\begin{tabular}{rlrrrrrrr}
\hline \multirow{2}{*}{ 65-69 } & & $\mathrm{p} 10$ & $\mathrm{p} 25$ & $\mathrm{p} 50$ & $\mathrm{p} 75$ & $\mathrm{p} 90$ & $\mathrm{p} 95$ & $\mathrm{p} 99$ \\
\cline { 2 - 8 } & MEPS sum & 89 & 535 & 1370 & 2826 & 4843 & 7693 & 14638 \\
& MEPS panel & 151 & 710 & 1455 & 2707 & 4755 & 7572 & 11278 \\
& & & & & & & \\
& MCBS sum & 141 & 581 & 1423 & 2964 & 5237 & 8020 & 18248 \\
& MCBS panel & 307 & 787 & 1653 & 3020 & 5268 & 7364 & 13547 \\
& & & & & & & \\
& & & & & & & \\
& MEPS sum & 171 & 696 & 1734 & 3455 & 6420 & 9326 & 16036 \\
& MEPS panel & 302 & 845 & 1923 & 3606 & 5889 & 8422 & 14092 \\
& & & & & & & \\
& MCBS sum & 206 & 727 & 1651 & 3317 & 6150 & 9030 & 20735 \\
& MCBS panel & 363 & 897 & 1868 & 3460 & 5974 & 8327 & 18257 \\
\hline
\end{tabular}

Note: MEPS sum quantiles are calculated by adding the quantiles from the 2002 and 2003 distributions. MEPS panel quantiles are calculated from the sum of spending in 2002 and 2003. Both use same panel observations. $\mathrm{N}=1574$ MEPS; $\mathrm{N}=6133$ MCBS

Source: Authors' calculations 
Table 11. Two year total out-of-pocket spending by individuals, 2002 and 2003, noninstitutionalized population, HRS 2004, and MEPS and MCBS 2002 \& 2003 panel. Weighted

\begin{tabular}{|c|c|c|c|c|c|c|c|c|c|c|}
\hline & & $\mathrm{N}$ & mean & p10 & p25 & p50 & p75 & p90 & p95 & p99 \\
\hline \multirow[t]{3}{*}{ 65-69 } & HRS & 3339 & 4034 & 20 & 450 & 1440 & 3600 & 7500 & 11570 & 43900 \\
\hline & MCBS & 1242 & 2570 & 307 & 787 & 1653 & 3020 & 5268 & 7364 & 13547 \\
\hline & MEPS & 388 & 2167 & 151 & 710 & 1455 & 2707 & 4755 & 7572 & 11278 \\
\hline \multirow[t]{3}{*}{ 70-74 } & HRS & 2605 & 4438 & 0 & 480 & 1500 & 3740 & 8640 & 13500 & 50640 \\
\hline & MCBS & 1461 & 2747 & 327 & 868 & 1792 & 3444 & 5764 & 8006 & 16672 \\
\hline & MEPS & 431 & 2808 & 330 & 942 & 2006 & 3663 & 5764 & 7408 & 15948 \\
\hline \multirow[t]{3}{*}{ 75-79 } & HRS & 1982 & 4774 & 2 & 600 & 1760 & 4100 & 8150 & 12030 & 43300 \\
\hline & MCBS & 1228 & 3132 & 385 & 963 & 1962 & 3486 & 6026 & 8216 & 24084 \\
\hline & MEPS & 326 & 2638 & 302 & 766 & 1788 & 3598 & 6057 & 8399 & 11786 \\
\hline \multirow[t]{3}{*}{$80-84$} & HRS & 1529 & 4726 & 88 & 600 & 1960 & 4300 & 9100 & 16840 & 57800 \\
\hline & MCBS & 1158 & 3032 & 405 & 978 & 2089 & 3730 & 6323 & 8750 & 17749 \\
\hline & MEPS & 246 & 4232 & 594 & 1245 & 2672 & 4531 & 7517 & 10186 & 21626 \\
\hline \multirow[t]{3}{*}{$85+$} & HRS & 1166 & 4797 & 0 & 504 & 1900 & 5150 & 10800 & 15000 & 50300 \\
\hline & MCBS & 1044 & 3354 & 436 & 986 & 2198 & 4214 & 7170 & 9397 & 19869 \\
\hline & MEPS & 183 & 3001 & 289 & 895 & 2202 & 4356 & 6135 & 9475 & 15190 \\
\hline \multirow[t]{3}{*}{ All } & HRS & 10621 & 4480 & 20 & 500 & 1620 & 4020 & 8400 & 13100 & 49220 \\
\hline & MCBS & 6133 & 2901 & 363 & 897 & 1868 & 3460 & 5974 & 8327 & 18257 \\
\hline & MEPS & 1574 & 2864 & 302 & 845 & 1923 & 3606 & 5889 & 8422 & 14092 \\
\hline
\end{tabular}

Source: Authors' calculations 


\begin{tabular}{|c|c|c|c|c|c|c|c|c|c|c|}
\hline \multirow{3}{*}{ 65-69 } & \multirow{3}{*}{$\begin{array}{l}\text { HRS } \\
\text { MCBS }\end{array}$} & \multirow{2}{*}{ N } & \multirow{2}{*}{$\frac{\text { mean }}{3421}$} & \multirow{2}{*}{$\begin{array}{r}\mathrm{p} 10 \\
0\end{array}$} & \multirow{2}{*}{$\begin{array}{l}\text { p25 } \\
340\end{array}$} & \multirow{2}{*}{$\begin{array}{r}\mathrm{p} 50 \\
1200\end{array}$} & \multirow{2}{*}{$\begin{array}{r}\mathrm{p} 75 \\
3000\end{array}$} & \multirow{2}{*}{$\begin{array}{r}\mathrm{p} 90 \\
7200\end{array}$} & \multirow{2}{*}{$\begin{array}{r}\mathrm{p} 95 \\
11380\end{array}$} & \multirow{2}{*}{$\begin{array}{r}\text { p99 } \\
39200\end{array}$} \\
\hline & & & & & & & & & & \\
\hline & & 1223 & 2140 & 227 & 614 & 1421 & 2429 & 4438 & 6344 & 11811 \\
\hline & MEPS & 265 & 1877 & 98 & 418 & 1213 & 2449 & 4110 & 6609 & 13546 \\
\hline \multirow[t]{3}{*}{$70-74$} & HRS & 2542 & 3190 & 0 & 374 & 1280 & 3500 & 7200 & 10400 & 29120 \\
\hline & MCBS & 1638 & 2576 & 244 & 698 & 1588 & 3067 & 5458 & 8161 & 15677 \\
\hline & MEPS & 316 & 2091 & 76 & 550 & 1296 & 2814 & 4695 & 6241 & 11286 \\
\hline \multirow[t]{3}{*}{$75-79$} & HRS & 2001 & 3588 & 0 & 480 & 1444 & 3600 & 7377 & 11450 & 31400 \\
\hline & MCBS & 1233 & 2655 & 325 & 824 & 1863 & 3302 & 5786 & 7876 & 13487 \\
\hline & MEPS & 258 & 2203 & 139 & 604 & 1393 & 2787 & 4995 & 6817 & 10924 \\
\hline \multirow[t]{3}{*}{$80-84$} & HRS & 1561 & 4254 & 48 & 500 & 1560 & 4175 & 8934 & 13000 & 37750 \\
\hline & MCBS & 1168 & 2817 & 341 & 852 & 1867 & 3424 & 5934 & 8603 & 16218 \\
\hline & MEPS & 181 & 2548 & 219 & 700 & 1660 & 2966 & 6362 & 7123 & 19232 \\
\hline \multirow[t]{3}{*}{$85+$} & HRS & 1112 & 4282 & 0 & 464 & 1680 & 4800 & 9700 & 16432 & 50922 \\
\hline & MCBS & 1018 & 3076 & 273 & 852 & 1920 & 3756 & 6435 & 9020 & 21863 \\
\hline & MEPS & 141 & 3003 & 339 & 925 & 1836 & 4181 & 6451 & 7415 & 23948 \\
\hline \multirow[t]{3}{*}{ All } & HRS & 10496 & 3615 & 0 & 418 & 1370 & 3600 & 7500 & 12072 & 37027 \\
\hline & MCBS & 6280 & 2573 & 267 & 731 & 1638 & 3082 & 5508 & 7876 & 15236 \\
\hline & MEPS & 1161 & 2247 & 139 & 609 & 1401 & 2879 & 4949 & 6938 & 13052 \\
\hline
\end{tabular}

Source: Authors' calculations

Table 13. Two-year total out-of-pocket spending by individuals in HRS and MCBS compared with MEPS: percent in excess (or deficit) of MEPS. Non-institutionalized population.

\begin{tabular}{lrrrrrr}
\hline & mean & $\mathrm{p} 50$ & $\mathrm{p} 75$ & $\mathrm{p} 90$ & $\mathrm{p} 95$ & $\mathrm{p} 99$ \\
\cline { 2 - 6 } 2002 \& 2003 & & & & & & \\
HRS & 56.4 & -15.8 & 11.5 & 42.6 & 55.5 & 249.3 \\
MCBS & 1.3 & -2.9 & -4.0 & 1.4 & -1.1 & 29.6 \\
MEPS & 0.0 & 0.0 & 0.0 & 0.0 & 0.0 & 0.0 \\
2000\& 2001 & & & & & & \\
HRS & 61.4 & -2.2 & 25.0 & 51.5 & 74.0 & 183.7 \\
MCBS & 14.1 & 16.9 & 7.1 & 11.3 & 13.5 & 16.7 \\
MEPS & 0.0 & 0.0 & 0.0 & 0.0 & 0.0 & 0.0 \\
\hline
\end{tabular}

Source: Authors' calculations 